\title{
Neighborhood Social Capital in Relation to Late HIV Diagnosis, Linkage to HIV Care, and HIV Care Engagement
}

\author{
Yusuf Ransome $^{1} \cdot$ Ichiro Kawachi $^{1} \cdot$ Lorraine T. Dean $^{2}$
}

Published online: 17 October 2016

(C) The Author(s) 2016. This article is published with open access at Springerlink.com

\begin{abstract}
High neighborhood social capital could facilitate earlier diagnosis of HIV and higher rates of linkage and HIV care engagement. Multivariate analysis was used to examine whether social capital (social cohesion, social participation, and collective engagement) in 2004/2006 was associated with lower 5-year average (2007-2011) prevalence of (a) late HIV diagnosis, (b) linked to HIV care, and (c) engaged in HIV care within Philadelphia, PA, United States. Census tracts $(\mathrm{N}=332)$. Higher average neighborhood social participation was associated with higher prevalence of late HIV diagnosis $(b=1.37$, $\mathrm{se}=0.32, \mathrm{p}<0.001)$, linked to HIV care $(\mathrm{b}=1.13$, $\mathrm{se}=0.20, \mathrm{p}<0.001)$ and lower prevalence of engaged in HIV care $(b=-1.16$, se $=0.30, p<0.001)$. Higher collective engagement was associated with lower prevalence of linked to HIV care $(b=-0.62, \quad$ se $=0.32$, $\mathrm{p}<0.05$ ). The findings of different directions of associations among social capital indicators and HIV-related outcomes underscore the need for more nuanced research on the topic that include longitudinal assessment across key populations.
\end{abstract}

Resumen Barrio alto de capital social podría facilitar el diagnóstico precoz del VIH y mayores tasas de vinculación y el compromiso de la atención del VIH. Se utilizó un análisis multivariado para examinar si capital social

Yusuf Ransome

yransome@hsph.harvard.edu

1 Department of Social and Behavioral Sciences, Harvard T.H. Chan School of Public Health, 677 Huntington Avenue, Kresge 7th Floor, Boston, MA 02115, USA

2 Department of Epidemiology, Johns Hopkins Bloomberg School of Public Health, Baltimore, MD, USA (cohesión social, la participación social y el compromiso colectivo) en 2004/2006 se asoció con una menor prevalencia promedio de 5 años (2007-2011) de (a) un diagnóstico tardío del VIH, (b) vinculado a la atención del VIH, y (c) que participan en la atención del VIH en Filadelfia, PA, Estados Unidos secciones censales $(\mathrm{N}=332)$. Mayor participación social nota promedio se asoció con una mayor prevalencia de diagnóstico tardío del VIH ( $b=1.37, \mathrm{SE}=0,32, \mathrm{p}<0,001)$, vinculado a la atención del VIH $(b=1.13, \mathrm{SE}=0,20, \mathrm{p}<0,001)$ y menor prevalencia de la dedicada a la atención del VIH $(b=-1,16$, $\mathrm{SE}=0,30, \mathrm{p}<0,001)$. Compromiso colectivo se asoció con una menor prevalencia de vinculado a la atención del VIH $(b=-0,62 ; S E=0,32, p<0,05)$. Los resultados de diferentes direcciones de las asociaciones entre los indicadores de capital social y los resultados relacionados con el VIH ponen de relieve la necesidad de una mayor matizada investigación sobre el tema que incluye evaluación longitudinal a través de poblaciones clave.

Keywords Social capital · Philadelphia, USA · Late HIV diagnosis $\cdot$ Neighborhood $\cdot$ HIV care engagement

\section{Introduction}

On average, $24 \%$ of persons newly diagnosed with HIV in the United States (U.S) receive a late HIV diagnosis, defined as being concurrently diagnosed with AIDS within 3 months of an initial diagnosis [1, 2]. Among the 1.2 million people living with HIV in the U.S., only $40 \%$ were engaged in HIV care and $37 \%$ prescribed anti-retroviral treatment [3]. Persons diagnosed with HIV late have lower likelihood of survival [4, 5] due to missing critical opportunities to fully benefit from anti-retroviral therapy 
$[6,7]$ that could reduce onward HIV transmission $[8,9]$. Improving population rates of linkage to, and sustained engagement in HIV care, is important to reduce virologic suppression among individuals [10] and reduce HIV burden in the community [11].

HIV outcomes in the population, including late HIV diagnosis, linkage to HIV care and engagement in HIV care are driven by social and structural factors that include racial residential segregation, concentrated poverty, and social and human capital investments at the ecological level [12-16]. Therefore, addressing social and structural factors could significantly improve HIV prevention above individuallybased biomedical and behavioral factors [17-19]. For instance, a recent economic evaluation of HIV prevention programs in Ontario, Canada found that province-wide community-based interventions that included increasing social support among residents, providing supportive housing, distributing condoms and needles and running antistigma campaigns, were associated with preventing 16,1672 new HIV infections, and saved the health care system approximately 6.5 billion dollars over 23 years [20].

Social capital can potentially be leveraged for HIV prevention interventions within communities [21-23]. Social capital is defined differently according to three theoretical perspectives dominant in the social science and public health literature, each of which suggests a set of theory-based social capital indicators. James Coleman defined social capital as the function of social structures that facilitate actions, obligations and expectations among actors and organizations that make it possible to achieve ends [24]. Indicators include trust of others, as well as institutions, and ability to sanction deviance and enforce social norms [24, 25]. Pierre Bourdieu defined social capital as the aggregate of actual or potential resources linked to a durable network of institutionalized relations of mutual recognition and acquaintance [26]. Indicators include aggregate social support, collective social order, and participation in community organizations or other collective activities [26, 27]. Robert Putnam defines social capital as features of social organization that improve efficiency of society by facilitating coordinated actions [28]. Indicators include membership in civic and social organizations, generalized trust, and trust of one's neighbor [29], which overlap and expand on the previous indicators. Moreover, social capital can be broadly defined as the structure of networks and collective resources within a community that individuals within that community can draw upon and benefit from [30, 31].

Each indicator of social capital may positively or negatively affect health and HIV outcomes in distinct or overlapping ways, therefore each are important to analyze separately. For instance, individuals in socially cohesive communities characterized by high trust and feelings of belongingness may project social norms that HIV infection is the result of promiscuous behavior, and may stigmatize individuals living with HIV who then may be less likely to seek HIV care and prevention resources [32, 33]. On the other hand, socially cohesive communities could foster a supportive environment for people to seek and utilize HIV testing [32].

Next, communities with high HIV prevalence but characterized by high coordinated and collective action, and high obligations and expectations of others may have higher prevalence of HIV care engagement. For instance, if an HIV testing and treatment center was to close in the neighborhood, but residents collectively agreed that this closure would make it difficult for HIV positive residents to obtain care, other residents (positive and HIV negative) could lobby to keep the center open.

Communities characterized by high resident participation in civic and social organizations (e.g., church and political groups) may also have lower late HIV diagnosis and higher HIV care engagement because of the potential for information and resource exchanges between HIV positive and negative individuals. Alternatively, higher community-level civic and social participation may be correlated with higher rates of late HIV diagnosis if participation is reflecting sero-converters who are getting tested as a function of the social support generated from participating in organizations that offer HIV testing. Relatedly, high HIV and related stigmas (e.g., of injection drug users) even within civically-engaged or cohesive communities may act as a barrier for neighbors engaging with one another to learn about HIV services [34]. Thus, HIV positive individuals may adopt an avoidance ritual [35] by deliberately seeking advice about HIV testing and actual HIV care outside of their community.

With respect to HIV outcomes, social capital is associated empirically with lower rates of infectious diseases [36], and HIV incidence and prevalence [37], through mechanisms such as higher awareness, knowledge and information sharing [38-40], HIV testing [41, 42], HIV disclosure [43], as well as lower HIV stigma and discrimination [42, 44, 45], and lower individual level risk behaviors that include infrequent condom use, and multiple sexual partners [37, 46-48].

Despite the theoretical links between social capital and HIV and the empirical evidence from international studies, there remains a paucity of published manuscripts on the topic in the U.S. Moreover, among the present studies, few have examined multiple social capital indicators in association with multiple HIV outcomes along the HIV care continuum (e.g., diagnosis, and care engagement) [49]. This analysis therefore investigates whether social capital is associated at the ecological level with prevalence of late HIV diagnosis, linked to HIV care, and engaged in HIV 
care in a large urban U.S. city. Results potentially can inform the state of HIV care engagement at both the local and national level.

\section{Methods}

The city of Philadelphia, Pennsylvania (PA) was the setting for this study. It is the fifth most populous city in the U.S. [50]. Published data from year 2013 showed that the prevalence of late HIV diagnosis (defined here as an AIDS diagnosis within 12 months of being newly diagnosed) was $25.5 \%$, which is on par with the national average for that period [51]. Data on neighborhood social capital were available for 332 out of 381 Census tracts, based Census 2000 boundaries. The Census tract is a very small geographic scale and valid neighborhood unit to study social capital and health [52], and HIV outcomes [53].

\section{Measures}

HIV surveillance data on the prevalence of persons with late HIV diagnosis, linked to HIV care, and engaged in HIV care at the ZIP code level were retrieved from HIVcontinuum.org, which is a web-database that contains several HIV outcomes from local health departments across five cities with high HIV burden [54]. HIV surveillance data were provided to HIVContinuum.org by the Philadelphia Department of Public Health, AIDS Activities Coordinating Office. These data contain the population-based sources of complete HIV infection and care engagement data reported as of 12/31/2012. Cases missing address or ZIP code at HIV diagnosis are excluded and cases diagnosed in a correctional facility were assigned to the ZIP code of the facility. For this study, only aggregate prevalence data and not actual count of cases were available.

Late HIV diagnoses represents the 5-year average (2007-2011) prevalence of adults/adolescents with an AIDS diagnosis within three months of newly diagnosed HIV.

Linked to HIV care represents the 5-year average (2007-2011) prevalence of adults/adolescents newly diagnosed with HIV with a reported CD4/viral load within 3 months of HIV diagnosis.

Engaged in HIV care represents the 5-year average (2007-2011) prevalence of adults/adolescents newly diagnosed with HIV from 2007-2011 and linked to HIV care with a reported CD4/viral load in year 2012.

Social capital data were retrieved from the Southeastern Pennsylvania Household Health Survey (SPHHS) administered by the Public Health Management Corporation [55]. Survey years 2004 and 2006 were combined, which were the only 2 years with social capital measures before the
HIV exposure data. The SPHHS is a Random Digit Dialing household telephone survey of health, social, and behavioral items asked of persons 18 years of age and older across the five major counties of greater Philadelphia area. In 2004, the survey achieved a Philadelphia sample of 4415 with $27 \%$ response rate, and in 2006, a sample of 4193 with a $24 \%$ response rate. The characteristics of the sample across survey waves are intentionally similar and so combining the data was not a threat to temporal variability. The SPHHS response rate falls within the range other wellused and respected community surveys that use randomdigit dialing [56-58] and that were issued during that time. As an additional strength, unlike some other communitybased surveys, SPHHS includes cellular phone users, which minimizes selection bias associated with randomdigit dialing techniques. There was an average of 30 respondents in each tract [inter-quartile range $(\mathrm{IQR})=21-39]$. Individuals had fairly stable residence patterns with 16 years being the average length of residence in the community [IQR $=3-27]$. There were five questions in the survey that capture social capital based on definitions corresponding to the three theoretical definitions described in the introduction. All the derived measures are validated based on face, convergent, and nomological validity criteria set forth by Lee and Kim [59].

Social cohesion was an indicator we created that aligns with definitions put forth by Robert Putnam. It was assessed by the following questions: Please tell me if you strongly agree, agree, disagree, or strongly disagree with the following statement: (1) I feel that I belong and am a part of my neighborhood, (2) most people in my neighborhood can be trusted. The third question was (3) please rate how likely people in your neighborhood are willing to help their neighbors with routine activities such as picking up their trash cans, or helping to shovel snow. Would you say that most people in your neighborhood are always, often, sometimes, rarely, or never willing to help their neighbor?. Prior research that used these data [52] suggested an oblique (promax) rotated principal components analysis (PCA), which demonstrated high reliability across these items (alpha $=0.76$ ).

To obtain Census tract averages for social cohesion, a multivariate regression model was used with the PCA scores as the outcome and covariates individual's age, sex, marital status, education, income, ratings of community, and rental or home ownership status. Empirical Bayes predicted values were estimated from the regression models, which produces aggregated scores removed of potential residual confounding from individual-level characteristics $[60,61]$. The predictions were then mean aggregated to the Census tract. Characteristics of the individual level sample used to create this aggregate measure are available as an appendix table. 
Social participation is an indicator that underpins both Putnam's and Coleman's definitions of social capital. This is a single item that queries individual's participation in both civic and social organizations, based on the question: how many local groups or organizations in your neighborhood do you currently participate in such as social, political, religious, school-related, or athletic organizations? The measure for this study is a predicted count of individuals responses derived from negative binomial regression adjusted for the same covariates used to predict social cohesion. The predictions were then mean aggregated to the Census tract.

Collective engagement is based on Coleman's definition of social capital about facilitating coordinated action to achieve certain ends. One item was available, which corresponded to the question, have people in your neighborhood ever worked together to improve the neighborhood? The measure for this study is a predicted probability of responding yes, and derived from logistic regression adjusted same covariates used to predict social cohesion. The predicted counts were then mean aggregated to the Census tract.

All social capital variables were aggregated to the Census tract using balancing weights provided in SPHHS, which accounts for the survey design by adjusting for sampling bias.

HIV testing and HIV treatment center accessibility. Increasing access to HIV testing and treatment are recommended for reducing late HIV diagnosis and improving linkage to and engagement in HIV care [62-64]. A list of HIV testing sites was generated by searching the National HIV and STD Testing web database [65] and a geographic database with locations of Ryan White HIV treatment centers across Philadelphia, PA $(\mathrm{N}=39)$ available from OpenDataPhilly.org [66]. Leadership of the Philadelphia AIDS Activities Coordinating Office validated which centers were present before year 2007. This corresponded to a final list of $\mathrm{N}=75$ centers after removing duplicates. Access to HIV testing and treatment is defined as the nearest distance (in miles) from the centroid of each Census tract to the closest HIV testing and treatment facility, as calculated by the Near Analysis Tool [67] in ArcGIS Desktop 10.2 [68]. Social capital may be associated with HIV testing in adjacent neighborhoods and individuals may receive HIV testing in neighborhoods adjacent to their residence. To account for this possibility, a spatially lagged HIV testing variable was derived based on the mean distance of HIV testing from centroids in adjacent neighborhoods. The variable was calculated as above, but incorporated adjacent tracts by using a Queen contiguitybased spatial weights matrix created in GeoDa software [69].

Assault rate was included as a covariate. Crime-one element of social disorder is associated with psychological distress that is linked to HIV risk behaviors [22]. Social capital is negatively associated with crime [70, 71] but it has been insufficiently researched with respect to HIV-related outcomes including HIV testing and linkage to HIV care [72-74]. Crime data were provided by the Philadelphia Police Department and made available through OpenDataPhilly.org [66]. The measure is the 5-year average rate (2007-2011) of all types of assault per 1000 Census 2010 population. Assault rates were log-transformed to address its right-skewed distribution.

The following socioeconomic and demographic covariates associated with late HIV and other HIV-related outcomes [75-78] were included: percent of black/African American residents, percent of males, percent of persons 25 years and older with less than a 9th grade education, percent of persons 16 years and older unemployed, median income, and percent of persons living in poverty within the Census tract. These data were retrieved from the Census 2000 estimates, Summary Files 3 Demographic Profiles 2 and 3 [79].

\section{Statistical Methods and Analysis}

\section{Areal Interpolation}

HIV surveillance data at the Census tract level were derived in two steps using the areal interpolation function in ArcGIS 10.2 software [67], which is a kriging-based method to smooth data across different spatial aggregation units and across units missing data [80]. First, using the HIV surveillance data at the ZIP code level, estimates for ZIP codes missing data were interpolated for each outcome separately (missing, $\mathrm{N}=6 / 45$ for late $\mathrm{HIV}$ diagnosis; $\mathrm{N}=1 / 45$ for linked to HIV care; and $\mathrm{N}=2 / 45$ for engaged in HIV care). The areal interpolation allowed one covariate, and income inequality, as measured with the GINI coefficient from the American Community Survey 5-year (2007-2011) estimates was selected because of prior research documenting an association with late HIV diagnosis [81]. Areal interpolation was employed with the following parameters: covariance semivariogram model; lag distance of 1000 meters; and search neighborhood parameters (maximum and minimum of four neighbors). Using those aforementioned parameters across each of the three HIV outcomes; in an iterative process, lag size and variogram model type were manipulated, separately for each outcome, to improve the fit and validity of the prediction model. For the late HIV diagnosis outcome, the predicted data fit best when the model type was "K-Bessel" and the number of lags was 15 and all other inputs were set to default. For the linked to HIV care and engaged in HIV care outcomes, the predicted data fit best when the model type was "Spherical" and the number of lags was 12, and all 
other inputs were set to default. Areal interpolation produces a smoothed surface map. In the second step, each smoothed surface map for the separate HIV outcomes was used to predict data to the Census tracts using the areal interpolation layer to polygons function [82].

\section{Descriptive Analysis}

Pearson correlations at the Census tract level were calculated to examine the associations among study covariates. Then the median prevalence and interquartile range for the three HIV outcomes across Census tracts were estimated. Next, choropleth maps were created in ArcGIS 10.2 of the prevalence of the HIV outcome data at the original level (i.e., ZIP codes) and the smoothed predicted estimates at the Census tract level with the locations of HIV testing and treatment centers overlaid. Mean social capital was mapped at the Census tract for the HIV outcomes and z-scores for the social capital variables because each indicator was measured originally on different scales.

Moran's I estimated the degree of spatial clustering for the HIV outcomes at the original ZIP code level and social capital at the Census tract level using a spatial weights matrix with nearest neighbor of $\mathrm{k}=4$ for ZIP codes, and $\mathrm{k}=7$ for Census tracts in the calculation. Moran's $I$ evaluates whether a pattern observed is clustered, dispersed, or random. A statistically significant value positive Moran's $I$ indicates that high values (i.e., rates or prevalence) spatially cluster near other high values, and that pattern is not random [83]. Last, Mann-Whitney $U$ tests were used to determine whether excluded Census tracts $(\mathrm{N}=49)$ were different from those included $(\mathrm{N}=332)$ on neighborhood unemployment, education, median income, and poverty level. Significance was assessed at alpha $p<0.05$.

\section{Multivariate Multivariable Analysis}

Multivariable analysis was performed in two steps. First, to determine the extent of spatial autocorrelation, spatial regression was run in GeoDa 1.01 software [69] for each outcome separately with social capital predictors, socioeconomic covariates and assault rate. Spatial regression models used a weights matrix for the Census tract with $(\mathrm{k}=7)$ nearest neighbors. Regression diagnostics helped determine which type of model significantly reduced any autocorrelation found. For late HIV diagnosis, an error model was determined best, and a spatial lag model for linked to HIV care and for engaged in HIV care. These models for each outcome were re-estimated with queen contiguity symmetrical weights. The predicted residuals for each outcome were used in the multivariable model corresponding to that outcome, but not displayed in results table because they have no interpretation.
Generalized structural equation (GSEM) models were generated in Stata 14.1 [84] to estimate a multivariate model where the three HIV outcomes were simultaneously predicted by the social capital variables and all covariates. Using a multivariate model allowed us to directly test whether the magnitude of social capital associations are equivalent across the three HIV outcomes. The guiding hypothesis was that social capital will have a larger impact on late HIV diagnosis than the other two outcomes. Specifically, social capital was expected to be more strongly related to late HIV diagnosis given that diagnosis is furthest upstream on the HIV care continuum. Therefore, social capital would be expected to have weaker associations on the linked to HIV care and engaged in HIV care outcomes, which are further downstream on the HIV continuum.

\section{Results}

\section{Spatial Interpolation Predicting Census Tract HIV Estimates}

Adequate fit and validity of the areal interpolation model is assessed by how close the mean-squared-standardized (RMSS) is to 1 and how similar the mean-squared (RMS) is to the average standard error (ASE). The fit of the ZIP code to Census tract estimates for late HIV diagnosis had RMSS value of 1.2, RMS of 7.8 and ASE of 7.5. For linked to HIV care, RMSS was 1.03, and RMS was 6.5 and ASE was 8.1. For engaged in HIV care, RMSS was 1.17 and RMS was 9.4 and ASE was 10.4 (results not displayed). Visual inspection of choropleth maps of the predicted surface for the Census tracts corroborated high consistency with the patterns observed for the data at the original ZIP code level (Fig. 1).

\section{Descriptive Associations}

Social cohesion had significant moderate positive correlation with social participation $(\mathrm{r}=0.69, \mathrm{p}<0.01)$ and collective engagement $(r=0.49, p<0.01)$, and collective engagement had a large and positive correlation with social participation $(\mathrm{r}=0.61, \mathrm{p}<0.01)$. All social capital variables were negatively correlated with poverty and education. The median prevalence of late HIV diagnosis within 3 months of an initial HIV infection for 2007-2011 was $26 \%$ (inter-quartile range (IQR) 23-28\%); medial prevalence of linkage to HIV care was $66 \%$, $(\mathrm{IQR}=64-69 \%)$ and median prevalence of engagement in HIV care was $69 \%$, (IQR $=66-71 \%$ ) (results not displayed). Late HIV diagnosis was significantly correlated with social cohesion $(r=0.15, p<0.01)$ and social 

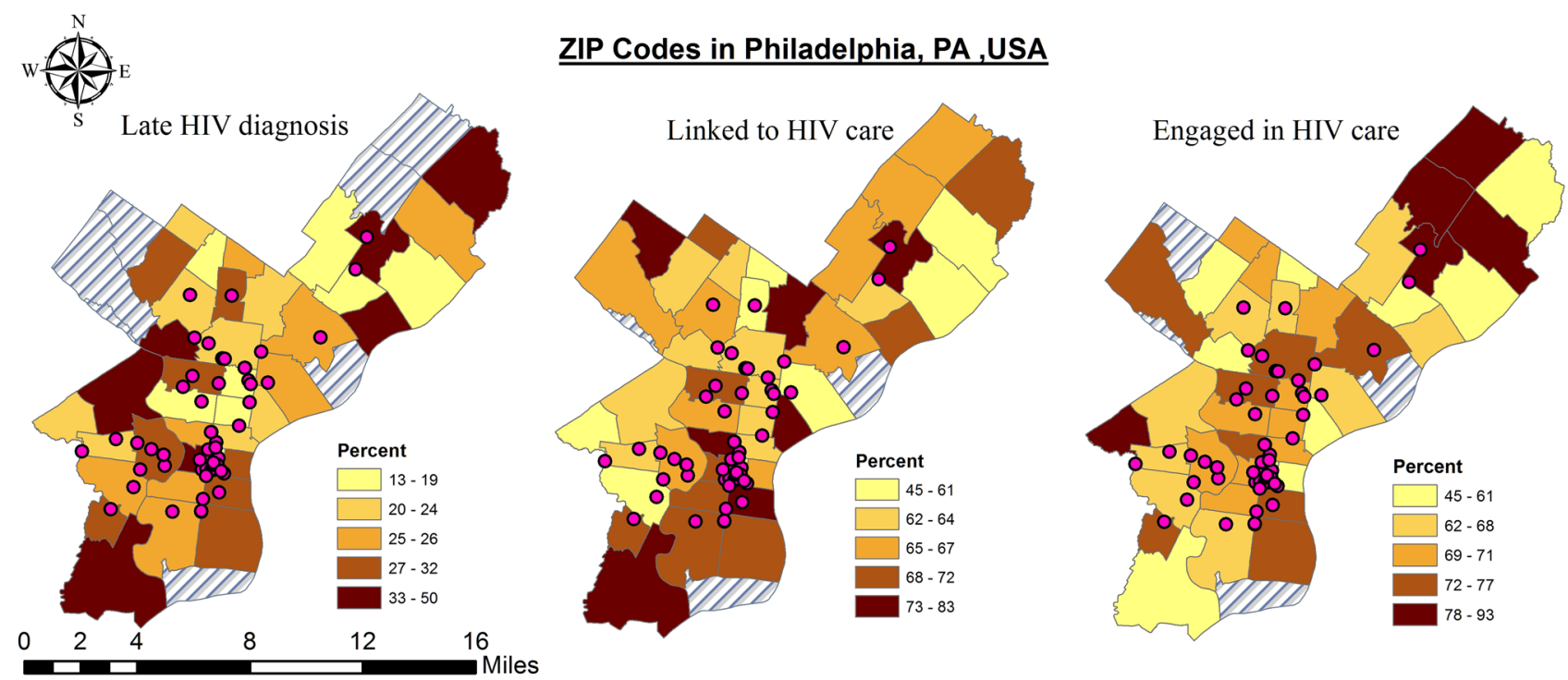

Census Tracts in Philadelphia, PA, USA
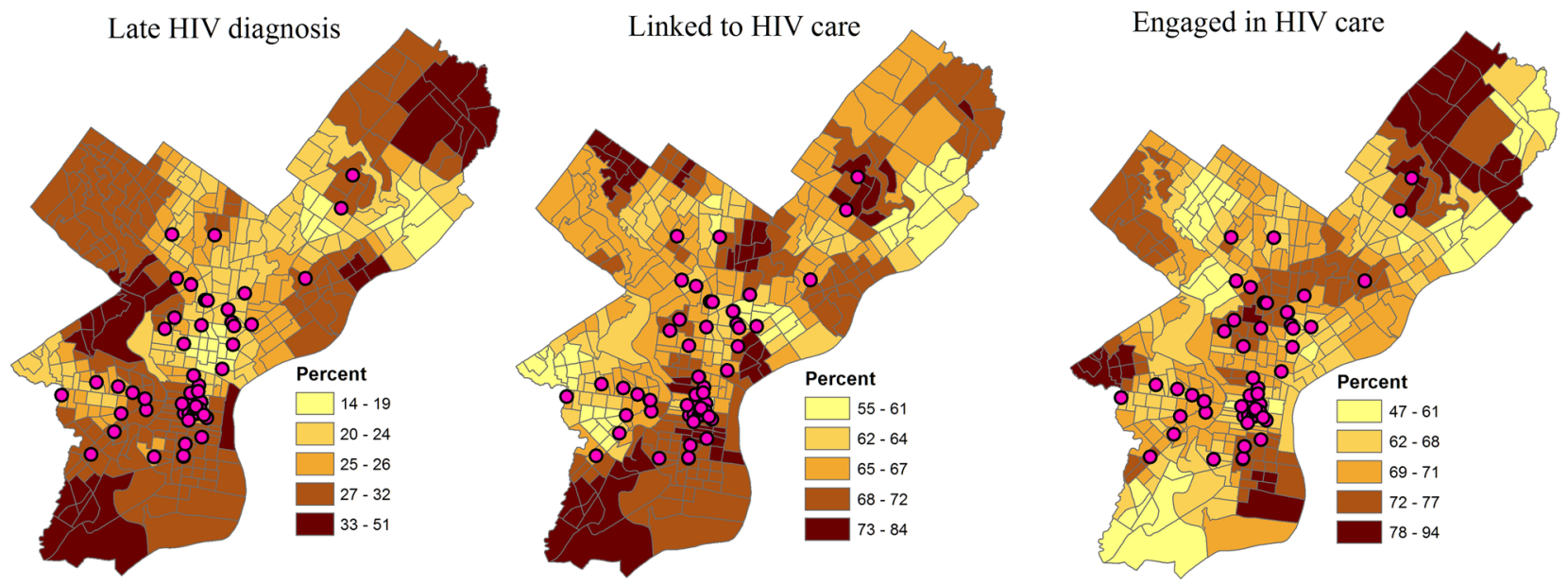

Social cohesion

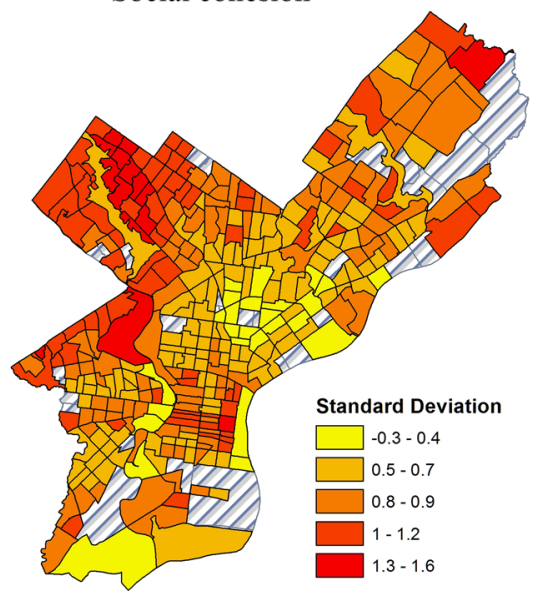

Social participation

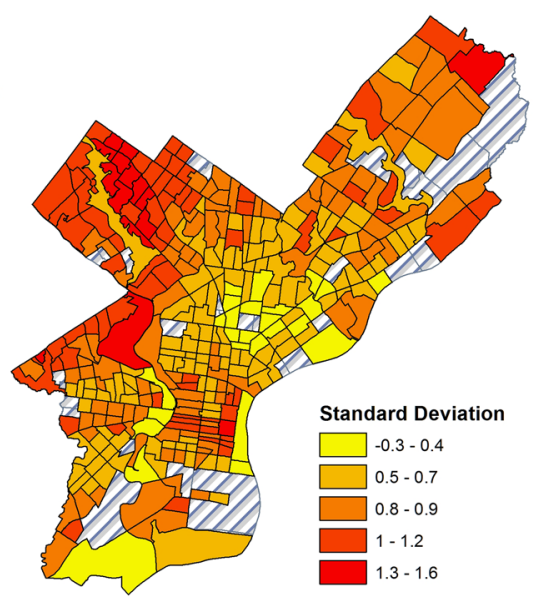

Collective engagement

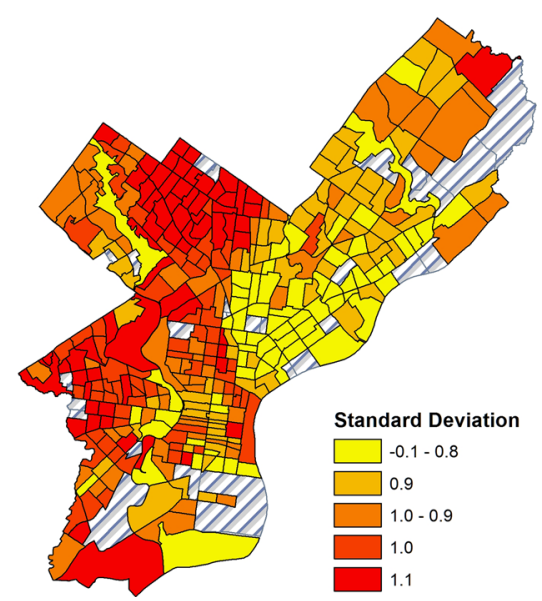

Fig. 1 Top row are original data at the ZIP code level $(\mathrm{N}=45)$ Philadelphia, PA, for 5-year average (2007-2011) HIV prevalence data from HIVcontinuum.org. Second row contains the areal interpolated data at the Census tract level $(\mathrm{N}=332)$. Third row contains social capital data at the Census tract level, Philadelphia, PA for year
2004/2006. Lighter color represents greater presence for the exposures and outcomes. UIIII Shaded regions are areas where data were not originally available. Filled circles represents HIV testing and HIV treatment centers $(\mathrm{N}=75)$, some locations are close and overlap, so not all points are visible (Color figure online) 
participation $(r=0.27, p<0.01)$. Engagement in HIV care was inversely correlated with social participation and collective efficacy $(r=-0.12, p<0.05)$. Distance to HIV testing center or treatment center was positively correlated with late HIV diagnosis $(\mathrm{r}=0.33, \mathrm{p}<0.01)$, and linked to HIV care $(r=0.15, p<0.05)$. Lagged HIV testing center was moderately correlated with linked to HIV care $(\mathrm{r}=0.34, \mathrm{p}<0.01)$ (Table 1$)$.

The Moran's I coefficients correspond to maps in Fig. 1. No significant clustering was observed for late HIV diagnosis $(I=-0.04, \quad \mathrm{p}=0.41)$, linked to HIV care $(I=-0.07, \mathrm{p}=0.30)$ or engaged in HIV care $(I=0.02$, $\mathrm{p}=0.31)$ at the ZIP code level. Significant clustering was observed at the Census tract level for all three HIV outcomes: late diagnosis $(I=0.70, \mathrm{p}<0.002)$, linkage to $(I=0.64, \mathrm{p}<0.002)$ and engagement in care $(I=0.55$, $\mathrm{p}<0.002)$, and for social cohesion $(I=-0.28$, $\mathrm{p}<0.002)$, social participation $(I=0.53, \mathrm{p}<0.002)$, and collective efficacy $(I=0.48, \mathrm{p}<0.002)$.

There were no differences in unemployment, education, median income or poverty between Census tracts included $(\mathrm{N}=332)$ and not included in the study $(\mathrm{N}=49)$ (results not displayed).

\section{Multivariate Association Among Social Capital and HIV Outcomes}

In multivariate analysis, the associations between social capital and the HIV outcomes are adjusted for HIV testing and treatment center, assault rate, and Census-tract sociodemographic and economic characteristics (hereafter, covariates) (Table 2). Social cohesion was not statistically associated with any of the HIV outcomes adjusting for covariates. A 1 standard deviation (SD) higher mean aggregate social participation was associated with slightly $1 \%$ higher prevalence of late HIV diagnosis $(b=1.37$, $\mathrm{se}=0.32, \mathrm{p}<0.001)$, persons linked to HIV care $(\mathrm{b}=1.13$, se $=0.20, \mathrm{p}<0.001)$, and lower prevalence of persons engaged in HIV care $(b=-1.16$, se $=0.30$, $\mathrm{p}<0.001$ ), adjusted for covariates. Collective engagement was statistically associated with $0.62 \%$ higher prevalence of persons engaged in HIV care $(b=0.62$, se $=0.27$, $\mathrm{p}<0.05$ ), adjusted for covariates.

Social participation was the only significant social capital indicator across all three HIV outcomes. We therefore focused our hypothesis test of higher magnitude of association for late HIV diagnosis vs the other HIV outcomes, to this indicator only. The magnitude [absolute value] of association between social participation on late HIV diagnosis $(b=1.37)$ was not statistically larger than the magnitude of the association with linked to HIV care $(b=1.13) \chi^{2}=0.31, p=0.58$, nor engaged in HIV care $(\mathrm{b}=1.16) \chi^{2}=0.21, \mathrm{p}=0.64$ (results not displayed).
Among the covariates, $1 \mathrm{SD}$ in distance to adjacent testing centers was associated with a $1 \%$ higher prevalence of late HIV diagnosis $(b=0.96, \quad s e=0.29$, $\mathrm{p}<0.05$ ) but not significantly associated with any other HIV outcome. A 1 SD increase in assault rate was marginally associated with lower prevalence of engaged in HIV care. Poverty and median income had no statistically independent associations with any of the HIV outcomes, adjusting for other covariates.

\section{Discussion}

This is the first study to examine multiple social capital indicators in relation to multiple HIV outcomes along the HIV care continuum in the U.S. Results indicate mixed evidence regarding the direction of association social capital should theoretically have on HIV outcomes. This ecological analysis of Census tracts in Philadelphia found no evidence that social cohesion was statistically related to late HIV diagnosis, although the association is the expected direction as found in a recent ZIP-code level ecological study conducted in New York City by Ransome, Galea, and Pabayo et al. [85]. That NYC-based study, however, differed from this study in several ways. First, while both this and the NYC-based study's definition of social cohesion includes a component of trust and neighbors' willingness to help, the third component differs. The social cohesion index in this study included a measure of belongingness while the NYC-based study asked about perceived close-knit relationships. The NYC-based also examined social capital among men and women, which contrasts with this study's use of aggregate data for the entire HIV infected population.

This study's findings indicate that each of the social capital indicators was positively correlated with HIV testing, and social cohesion was negatively correlated with crime. These directions are consistent with associations reported in prior research [41, 42, 71]. However, findings in this study cannot preclude reverse causality given the cross-sectional nature of these data.

The present study's results show that higher social participation was associated with higher late HIV diagnosis. The direction found in this study is similar to the direction found by Ransome, Galea and Pabayo et al. among men [85], measured by a civic engagement indicator that includes a component of participating in local organizations, just as in this study. While in general, social capital would be expected to be associated with lower late HIV diagnosis, the directions found in these two studies may indicate a complex pattern more detailed data are required to answer. For instance, in both ours and the NYC-based study, information on the type of organizations 


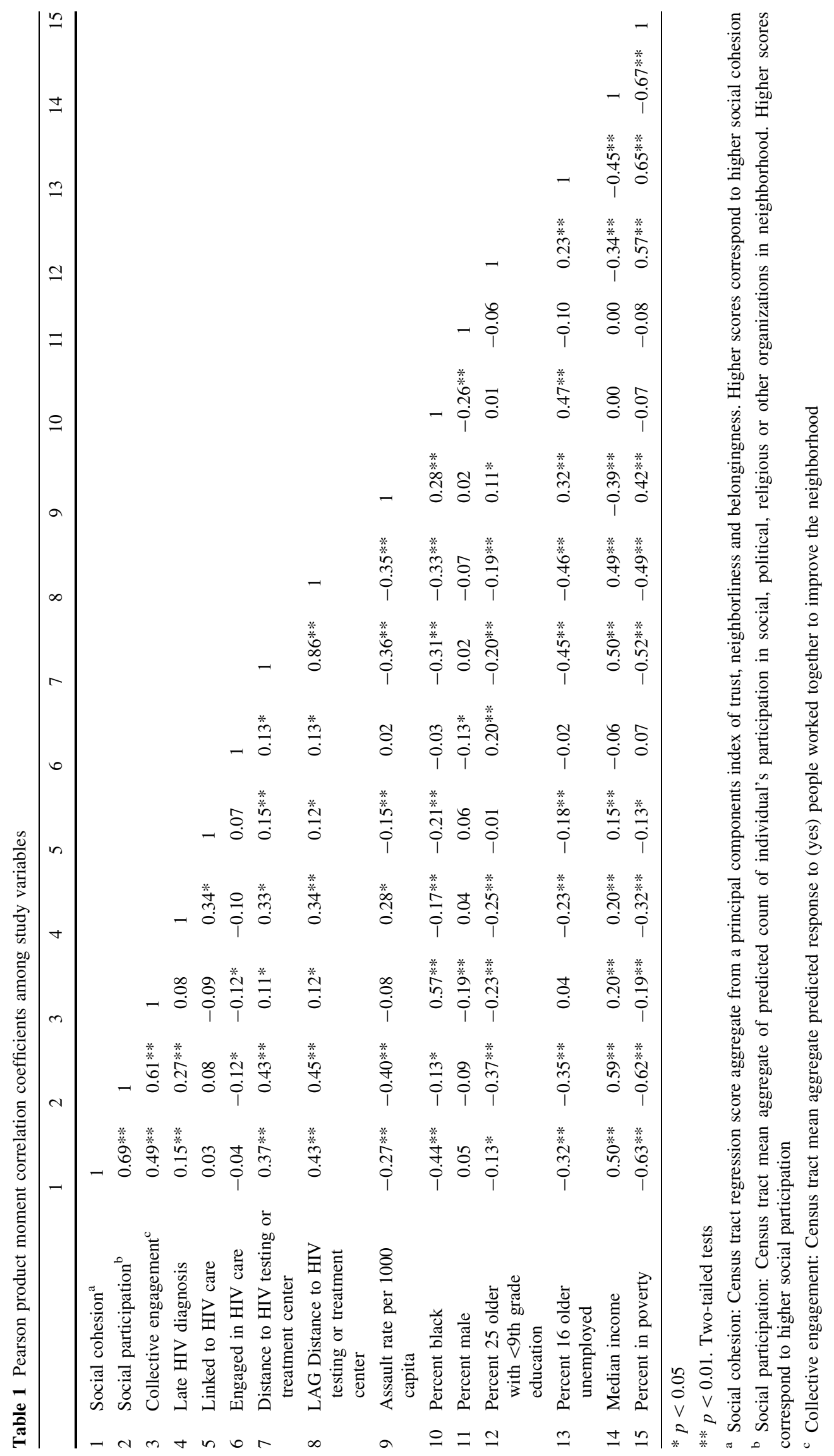


Table 2 Association between social capital and selected HIV outcomes across the HIV treatment cascade in Philadelphia neighborhoods $(\mathrm{N}=332$ Census tracts)

\begin{tabular}{|c|c|c|c|}
\hline Mean (SD) of each variable ${ }^{\dagger}$ & $\begin{array}{l}\text { Late HIV } \\
\text { diagnosis b (se) }\end{array}$ & $\begin{array}{l}\text { Linked to HIV } \\
\text { care b (se) }\end{array}$ & $\begin{array}{l}\text { Engaged in HIV } \\
\text { care } \mathrm{b}(\mathrm{se})\end{array}$ \\
\hline Social cohesion ${ }^{\mathrm{a}, \mathrm{d}}, 9.28(0.76)$ & $-0.45(0.37)$ & $-0.43(0.31)$ & $0.16(0.36)$ \\
\hline Social participation ${ }^{\mathrm{b}, \mathrm{d}}, 0.79(0.20)$ & $1.37(0.32)^{* * *}$ & $1.13(0.20)^{* * *}$ & $-1.16(0.30)^{* * *}$ \\
\hline Collective engagement ${ }^{\mathrm{c}, \mathrm{d}}, 0.65(0.07)$ & $-0.63(0.38)$ & $-0.62(0.32)^{*}$ & $-0.01(0.36)$ \\
\hline $\begin{array}{l}\text { Distance (in miles) to nearest HIV testing center or } \\
\text { treatment facility, } 1.14(0.97)\end{array}$ & $-0.10(0.28)$ & $-0.12(0.24)$ & $0.62(0.27)^{*}$ \\
\hline $\begin{array}{l}\text { LAG Distance (in miles) to nearest HIV testing center or } \\
\text { treatment facility }{ }^{\mathrm{e}}, 1.07(0.72)\end{array}$ & $0.96(0.29) * *$ & $0.30(0.24)$ & $0.42(0.27)$ \\
\hline Assault rate per 1000 capita, 37.01 (36.71) & $-0.03(0.18)$ & $-0.12(0.15)$ & $-0.08(0.02)^{* *}$ \\
\hline Percent black, 45.22 (37.05) & $0.09(0.31)$ & $-0.30(0.26)$ & $-0.05(0.30)$ \\
\hline Percent male, 46.76 (5.73) & $0.00(0.20)$ & $0.11(0.17)$ & $0.04(0.20)$ \\
\hline Percent 25 older with $<9$ th grade education, $7.50(6.43)$ & $-1.07(0.22)^{* * *}$ & $0.14(0.18)$ & $0.94(0.21)^{* * *}$ \\
\hline Percent 16 older unemployed, 6.05 (3.07) & $-0.06(0.20)$ & $-0.48(0.17)^{* *}$ & $-0.30(0.19)$ \\
\hline Median income, $\$ 32,291(\$ 18,882)$ & $-0.38(0.22)$ & $-0.06(0.18)$ & $-0.21(0.21)$ \\
\hline Percent in poverty, 19.11 (14.75) & $0.09(0.28)$ & $0.47(0.24)$ & $-0.13(0.27)$ \\
\hline
\end{tabular}

$b$ beta coefficient, $S E$ standard error

$* p<0.05$

$* * p<0.01$

$* * * p<0.001$

$\dagger$ All predictors have been z-scored transformed to a mean of 0 and standard deviation (SD) of 1 , for the multivariable analysis

a Social cohesion: Census tract regression score aggregate from a principal components index of trust, neighborliness and belongingness

b Social participation: Census tract mean aggregate of predicted count of individual's participation in social, political, religious or other organizations in neighborhood

${ }^{c}$ Collective engagement: Census tract mean aggregate predicted response to (yes) people worked together to improve the neighborhood

${ }^{\mathrm{d}}$ Coded such that it corresponds to higher social capital

e LAG are for distance of the adjacent neighbors based on Queen Contiguity weights matrix at the Census tract level

where individuals participated was not assessed. Social capital generated across different types of organizational participation matters for HIV outcomes.

It is therefore plausible that the positive association between social participation/civic engagement and late HIV diagnosis could reflect participation in different type of organizations and potentially higher membership in organizations with high HIV testing norms. For instance, Campbell, Williams and Gilgen study of social capital and HIV in South Africa found that for men, participation in stokvels (savings club with social activities) was associated with higher likelihood of individuals being HIV+, but participation in sports clubs were associated with lower likelihood of members being HIV+ [86].

The present study may be the first to document that social capital is empirically associated with prevalence of persons linked to HIV care and engagement of HIV care in the community. Consistent with what theory would predict; higher social participation was associated with higher prevalence of persons linked to HIV care. The negative association between social participation and prevalence of persons engaged in HIV care could reflect a diminishing return of social capital's association on outcomes very close along the HIV care cascade. Specifically, high social capital may facilitate higher linkage to care within three months but may those benefits may diminish between 4 and 12 months - the operational time period that distinguishes between linked and engaged in HIV care.

Without longitudinal data on types of organizational participation, results are limited to speculation. One potential explanation for differences in direction of association is that community-level and individual-level psychosocial mechanisms such as information exchange and self-esteem and coping $[32,87,88]$ facilitate protective associations on short-term behaviors such as diagnosis and being linked to care but not long-term behaviors. Next, it is plausible that social capital may become disruptive [89] in the long term and associated with HIV risk behaviors that encompass the dark side or negative aspects of social capital [90]. It is also possible that social participation may have changed. For instance, social participation during the 9 months between being linked to HIV care and engaged in HIV care could have changed from organizations characterized by HIV prevention to organizations characterized by HIV risk and delinquency. 
Others have noted that social capital may not benefit all groups [91] and consequently may not be associated with lower HIV risk [92]. For instance, while religious institutions has been a space where many blacks traditionally have drawn social capital from [93], this same space has been a source of stigma for black men who have sex with men (MSM) [94] - the subpopulation with highest rates of incidence and late HIV among blacks [95].

There was limited support that collective engagement was associated lower prevalence of persons linked to HIV care in the Census tract. Again, these findings run contrary to what theory would predict. These findings may be related to limitations assessing social capital and HIV using cross-sectional data. For instance, in areas with high disease burden; high social capital may be the result of community members becoming more collectively engaged as a way to draw attention to its needs and secure health resources, which has been found in other chronic disease studies in Philadelphia, PA [52, 96, 97]. It is possible therefore that rates of linkage to HIV care were low in the past and that motivated community members to coalesce to resolve the problem, which showed up in cross-sectional studies as high social capital in high-prevalence areas.

Another possibility is that higher rates of collective engagement in community and social organizations reflect need by persons already afflicted with high HIV burden within impoverished communities [98]. For instance, one study found that food insecurity among people living with HIV/AIDS was associated with residence in neighborhoods with poverty and with poorer HIV treatment adherence [99]. These explanations could also potentially explain why collective engagement was associated with lower linkage to HIV care.

This study finds no evidence to support the hypothesis that social capital would have a larger magnitude of association on late HIV diagnosis given it is further upstream the HIV care continuum than linked to and engaged in HIV care. These findings potentially indicate that social capital could be leveraged as an HIV prevention strategy at any of these points along the HIV care continuum. One alternative explanation could be that the impact of social capital on HIV care engagement is mediated through an indirect impact of social capital on late HIV diagnosis. However, that inquiry was outside the scope of this study and would require temporal data on the outcomes and path mediation analysis.

The findings and meaning of our results should be considered in context of the following study limitations. While our social capital measures were valid indicators based on the social capital theory, the composition of our measures such as social cohesion and collective engagement do not correspond fully to other validated social capital scales used in the literature [100]. However, the availability of social capital measures differ across surveys, which is one limitation of social capital research [101, 102] in general. Nevertheless, the measures used in this study can help to build evidence in the literature with regard to the utility in social science research.

This study used a single-item measure we called collective engagement to reflect James Coleman's definition of social capital as engagement among actors to achieve certain ends. Following recommendations on assessing the validity of social capital measures put forth by Lee and Kim [59], this measure shows strong face-validity given that the question wording directly asks about people working together. Second, the large (i.e., $r=0.49$ and $r=0.61)$ correlations of collective engagement with the other two social capital measures suggests these are capturing the underlying phenomena of social capital. Third, the collective engagement measure demonstrates nomological validity because like social cohesion and social participation, it also has a negative correlation with violent crime - a direction expected and empirically demonstrated with social capital [59].

Social capital stratified by socio-economic or demographic subgroup or disaggregate types of social participation could not be assessed. The quantity and quality of social capital varies across strata such as social class [25, 103]. Therefore, subgroup differences in social capital may moderate the associations on health. For instance, Hutchinson, Putt and Dean et al. found that neighborhood racial composition moderated the association between social capital and mortality rates in Philadelphia, PA [104]. The association between social capital and health [105] and HIV [106] could be moderated by socio-economic and demographic characteristics of group membership especially for persons who are marginalized or excluded from membership via competition for resources [107-109].

Next, only publicly available HIV surveillance data at the aggregate level were available. Therefore, data could not be stratified by sex nor race nor transmission status to investigate potential differences across key population groups. Given the limited the ability to distinguish the types of social participation and no data by race and transmission group, we could not discriminate the potential divergent associations. For instance, it is possible that social participation from religious compared to secular organizations have different impacts on HIV for Black MSM groups across race and transmission status [85].

HIV prevalence data included cases diagnosed in correctional facilities and assigned to the ZIP code of the facility. Unfortunately, those cases could not be identified in these aggregated data and thus could not be removed. This potentially is a problem because the SPHHS study did not assess social capital or other measures among institutional populations. Persons diagnosed within correctional 
facilities will typically have consistent access to healthcare, which may mean that late HIV diagnosis rates and engagement in care could be artificially higher in ZIP codes with correctional facilities. Without disaggregated data, this analysis could not assess the degree of potential bias in associations reported.

The generalizability of study results to other U.S. settings or ecological levels is limited. Specifically, as seen with differences in spatial clustering of HIV at Census tract versus ZIP code; correlations and regression estimates will also vary across ecological units due to the modifiable unit areal unit problem (MAUP) [110]. However, this study did not re-aggregate data but rather smoothed the data over a continuous geographic surface, which mitigates some limitations within the MAUP [111]. Moreover, Census tract is a particularly relevant unit for studying social relationships at the ecological level [112] given lower heterogeneity and greater temporal spatial stability than ZIP codes [113]. Using HIV surveillance data at a very fine geographic level also enhances the opportunity for precise geographically targeted HIV prevention initiatives [114].

Some strengths of this analysis include building a complex database of HIV surveillance, Census, administrative, and household survey data to address the paucity of research on social capital and HIV in the U.S. The methods used to interpolate HIV data across geography demonstrate the feasibility of utilizing geospatial technology to enhance HIV prevention research using publicly available data. Next, these results contributed to the broader literature and advanced prior ecological studies by examining multiple social capital indicators across multiple HIV outcomes along the HIV care continuum. Additionally, the study validated the new measures of social capital through several criterion, which included face validity, convergent validity, nomological validity, and predictive validity [59].

\section{Conclusion}

This study highlights that neighborhood social capital is ecologically associated with population level HIV/AIDS outcomes along the care cascade in a large urban U.S. city. Differences in which social capital indicators were significant along with varying directions of associations across social capital indicators and HIV outcomes highlight the complexity of this research. The results lay a foundation for future studies to assess the relationship between multiple dimensions of social capital and HIV outcomes using prospective study design, multilevel methods, and across the intersection of race and transmission group.

Acknowledgments Y. Ransome was supported by the Alonzo Smythe Yerby Postdoctoral Fellowship at the Harvard T.H. Chan
School of Public Health. L. Dean was supported in part by the National Institutes of Health and National Cancer Institute Grant No. 1K01CA184288 and the Johns Hopkins University Center for AIDS Research (P30AI094189). The authors thank Coleman Terrell, Director of the Philadelphia AIDS Activities Coordinating Office for input on the history of HIV testing centers in Philadelphia.

\section{Compliance with Ethical Standards}

Conflict of Interest The authors declare that they have no conflict of interest.

Ethical approval This article does not contain any studies with human participants performed by any of the authors.

Informed Consent Informed consent was obtained from all individual participants included in the study.

Open Access This article is distributed under the terms of the Creative Commons Attribution 4.0 International License (http://crea tivecommons.org/licenses/by/4.0/), which permits unrestricted use, distribution, and reproduction in any medium, provided you give appropriate credit to the original author(s) and the source, provide a link to the Creative Commons license, and indicate if changes were made.

\section{References}

1. Centers for Disease Control and Prevention. Today's HIV/AIDS Epidemic. HIV/AIDS Fact Sheets 2015.

2. Hall HI, Tang T, Espinoza L. Late diagnosis of HIV infection in metropolitan areas of the United States and Puerto Rico. AIDS Behav. 2015:1-6.

3. Bradley H, Hall I, Wolitski R, Van Handel MM, Stone AE, LaFlam M, et al. Vital signs: HIV diagnosis, care, and treatment among persons living with HIV-United States, 2011. Morb Mortal Wkly Rep. 2014;63:1113-8.

4. Shrosbree J, Campbell LJ, Ibrahim F, Hopkins P, Vizcaychipi $\mathrm{M}$, Strachan S, et al. Late HIV diagnosis is a major risk factor for intensive care unit admission in HIV-positive patients: a single centre observational cohort study. BMC Infect Dis. 2013;13:23.

5. Montlahuc C, Guiguet M, Abgrall S, Daneluzzi V. Impact of late presentation on the risk of death among HIV-infected people in France (2003-2009). J Acquir Immune Defic Synd. 2013;64:197-203.

6. Sabin CA, Smith CJ, Gumley H, Murphy G, Lampe FC, Phillips $\mathrm{AN}$, et al. Late presenters in the era of highly active antiretroviral therapy: uptake of and responses to antiretroviral therapy. AIDS. 2004;18:2145-51.

7. Mukolo A, Villegas R, Aliyu M, Wallston KA. Predictors of late presentation for HIV diagnosis: a literature review and suggested way forward. AIDS Behav. 2013;17:5-30.

8. Cohen MS, Chen YQ, McCauley M, Gamble T, Hosseinipour MC, Kumarasamy N, et al. Prevention of HIV-1 infection with early antiretroviral therapy. N Engl J Med. 2011;365:493-505.

9. Tanser F, Bärnighausen T, Grapsa E, Zaidi J, Newell M-L. High coverage of ART associated with decline in risk of HIV acquisition in rural KwaZulu-Natal, South Africa. Science. 2013;339:966-71.

10. Dombrowski J, Kent J, Buskin S, Stekler J, Golden M. Population-based metrics for the timing of HIV diagnosis, engagement in HIV care, and virologic suppression. AIDS. 2012;26:77-86. 
11. Mayer KH. Introduction: linkage, engagement, and retention in HIV care: essential for optimal individual-and community-level outcomes in the era of highly active antiretroviral therapy. Clin Infect Dis. 2011;52:S205-7.

12. Nash D, Elul B. The impact of HIV on cities in the era of treatment: a global perspective. Technol Soc. 2006;28:195-223.

13. Bärnighausen T, Tanser F, Herbst K, Mutevedzi T, Mossong J, Newell M-L. Structural barriers to antiretroviral treatment: a study using population-based CD4 cell count and linked antiretroviral treatment programme data. Lancet 2013;382.

14. Johnston D. Economics and HIV: the sickness of economics. New York: Routledge; 2013.

15. Adimora AA, Schoenbach VJ. Social context, sexual networks, and racial disparities in rates of sexually transmitted infections. J Infect Dis. 2005;191:S115-22.

16. Bowleg L, Neilands TB, Tabb LP, Burkholder GJ, Malebranche DJ, Tschann JM. Neighborhood context and black heterosexual men's sexual HIV risk behaviors. AIDS Behav. 2014;18:2207-18.

17. Wohlfeiler D, Ellen JM. The limits of behavioral interventions for HIV prevention. In: Cohen L, editor. Prevention is primary: strategies for community well being. San Francisco: JosseyBass; 2007. p. 329-47.

18. Buot M-LG, Docena JP, Ratemo BK, Bittner MJ, Burlew JT, Nuritdinov AR, et al. Beyond race and place: distal sociological determinants of HIV disparities. PLoS One 2014;9.

19. Richman DD, Margolis DM, Delaney M, Greene WC, Hazuda D, Pomerantz RJ. The challenge of finding a cure for HIV infection. Science. 2009;323:1304-7.

20. Choi SK, Holtgrave DR, Bacon J, Kennedy R, Lush J, McGee F, et al. Economic evaluation of community-based HIV prevention programs in Ontario: evidence of effectiveness in reducing HIV infections and health care costs. AIDS Behav. 2015;20:1143-56.

21. Latkin CA, Knowlton A. Micro-social structural approaches to HIV prevention: a social ecological perspective. AIDS Care. 2005; 17:102-13.

22. Latkin C, German D, Vlahov D, Galea S. Neighborhoods and HIV: a social ecological approach to prevention and care. Am Psychol. 2013;68:210-24.

23. Parkhurst JO. HIV prevention, structural change and social values: the need for an explicit normative approach. J Int AIDS Soc. 2012;15:17367.

24. Coleman JS. Social capital in the creation of human capital. Am J Sociol. 1988;94:S95-120.

25. Macinko J, Starfield B. The utility of social capital in research on health determinants. Milbank Q. 2001;79:387-427.

26. Bourdieu P, Wacquant L. An invitation to reflexive sociology. Chicago: University of Chigago Press; 1992.

27. Carpiano RM. Toward a neighborhood resource-based theory of social capital for health: can Bourdieu and sociology help? Soc Sci Med. 2006;62:165-75.

28. Putnam R. Making democracy work: civic traditons in modern Italy. Princeton: Princeton University Press; 1993.

29. Putnam R. Bowling alone: America's declining social capital. J Democr. 1995;6:65-78.

30. Kawachi I, Berkman L. Social cohesion, social capital and health. In: Kawachi I, Berkman L, Glymour M, editors. Social epidemiology. 2nd ed. New York: Oxford University Press; 2014. p. 291-319.

31. Kawachi I, Subramanian SV, Kim D. Social capital and health. New York: Springer; 2008. p. 291.

32. Cene CW, Akers AY, Lloyd SW, Albritton T, Hammond WP, Corbie-Smith G. Understanding social capital and HIV risk in rural African American communities. J Gen Intern Med. 2011;26:737-44.
33. Campbell C, Skovdal M, Gibbs A. Creating social spaces to tackle AIDS-related stigma: reviewing the role of church groups in Sub-Saharan Africa. AIDS Behav. 2010;15:1204-19.

34. Sivaram S, Zelaya C, Srikrishnan A, Latkin C, Go V, Solomon $\mathrm{S}$, et al. Associations between social capital and HIV stigma in Chennai, India: considerations for prevention intervention design. AIDS Educ Prev. 2009;21:233-50.

35. Goffman E. Interaction ritual: essays in face-to-face behavior. New Brunswick: Transaction Publishers, [1967] Aldine Pub; 2005.

36. Holtgrave D, Crosby R. Social capital, poverty, and income inequality as predictors of gonorrhoea, syphilis, chlamydia and AIDS in the United States. Sex Transm Infect. 2003;79:62-4.

37. Pronyk PM, Harpham T, Morison LA, Hargreaves JR, Kim JC, Phetla G, et al. Is social capital associated with HIV risk in rural South Africa? Soc Sci Med. 2008;66:1999-2010.

38. Nguyen H, Shiu C, Peters C. The relationship between Vietnamese youths' access to health information and positive social capital with their level of HIV knowledge: results from a national survey. Vulnerable Child. 2015;10:67-78.

39. Morrison SD, Howard R, Hardy C, Stinson B. Social capital, health and HIV awareness of girls in a rural caribbean community. Int Electron J Health. 2005;8:135-45.

40. Jesmin SS, Chaudhuri S. Why do some women know more? An exploration of the association of community socioeconomic characteristics, social capital, and HIV/AIDS knowledge. Women Health. 2013;53:669-92.

41. Karim QA, Meyer-Weitz A, Mboyi L, Carrara H, Mahlase G, Frohlich JA, et al. The influence of AIDS stigma and discrimination and social cohesion on HIV testing and willingness to disclose HIV in rural KwaZulu-Natal, South Africa. Glob Public Health. 2008;3:351-65.

42. Fonner VA, Kerrigan D, Mnisi Z, Ketende S, Kennedy CE, Baral S. Social cohesion, social participation, and HIV related risk among female sex workers in swaziland. PLoS One. 2014;9:e87527.

43. Wouters E, Meulemans H, van Rensburg HCJ. Slow to share: social capital and its role in public HIV disclosure among public sector ART patients in the free State province of South Africa. AIDS Care. 2009;21:411-21.

44. Chiu J, Grobbelaar J, Sikkema K, Vandormoel A, Bomela N, Kershaw T. HIV-related stigma and social capital in South Africa. AIDS Educ Prev. 2008;20:519-30.

45. Nhamo-Murire M, Campbell C, Gregson S. Community group membership and stigmatising attitudes towards people living with HIV in eastern Zimbabwe. J Community Health. 2014;39:72-82.

46. Crosby RA, Holtgrave DR, DiClemente RJ, Wingood GM, Gayle JA. Social capital as a predictor of adolescents' sexual risk behavior: a state-level exploratory study. AIDS Behav. 2003;7:245-52.

47. Cain D, Pitpitan E, Eaton L, Carey K, Carey M, Mehlomakulu $\mathrm{V}$, et al. Collective efficacy and HIV prevention in South African townships. J Community Health. 2013;38:885-93.

48. Kerrigan D, Witt S, Glass B, Chung SE, Ellen J. Perceived neighborhood social cohesion and condom use among adolescents vulnerable to HIV/STI. AIDS Behav. 2006;10:723-9.

49. Mugavero MJ, Amico KR, Horn T, Thompson MA. The state of engagement in HIV care in the United States: from cascade to continuum to control. Clin Infect Dis. 2013;58:1164-71.

50. Bureau USC. Ten U.S. cities now have 1 million people or more; California and Texas each have three of these places. In: 2015. pp. Release Number: CB15-89.

51. AIDSvu. City and state profiles: Philadelphia, Pennsylvania. In: AIDSVu; 2016. 
52. Dean L, Subramanian S, Williams DR, Armstrong K, Charles CZ, Kawachi I. The role of social capital in African-American women's use of mammography. Soc Sci Med. 2014;104:148-56.

53. Eberhart MG, Yehia BR, Hillier A, Voytek CD, Blank M, Frank I, et al. Behind the cascade: analyzing spatial patterns along the HIV care continuum. J Acquir Immune Defic Synd. 2013;64:S42.

54. Sanchez TH, Sullivan P. HIV continuum-mapping the HIV care continuum. Atlanta: AIDSVu; 2015.

55. Community PHMC. Southeastern Pennsylvania Household Health Survey. In: nd.

56. California Health Interview S. Response Rates. In: Cervantes IF, Norman GJ, Brick MJ, Edwards S, editors. CHIS 2007 methodology series. Los Angeles: UCLA Center for Health Policy Research; 2009.

57. Lee E, Brown ER, Grant D, Belin TR, Brick JM. Exploring nonresponse bias in a health survey using neighborhood characteristics. Am J Public Health. 2009;99:1811-7.

58. Centers for Disease C, Prevention. 2008 Behavioral risk factor surveillance system (BRFSS). Summary data quality report. Atlanta: U.S. Department of Health and Human Services, Centers for Disease Control and Prevention; 2009.

59. Lee C-J, Kim D. A comparative analysis of the validity of US state-and county-level social capital measures and their associations with population health. Soc Indic Res. 2013;111:307-26.

60. Harpham T. The measurement of community social capital through surveys. In: Kawachi I, Subramanian SV, Kim D, editors. Social capital and health. New York: Springer; 2008. p. $51-62$.

61. Harpham T, Grant E, Thomas E. Measuring social capital within health surveys: key issues. Health Policy Plan. 2002;17:106-11.

62. Layer EH, Kennedy CE, Beckham SW, Mbwambo JK, Likindikoki S, Davis WW, et al. Multi-level factors affecting entry into and engagement in the HIV continuum of care in Iringa, Tanzania. PLoS One 2014;9.

63. Kelen GD, Hsieh YH, Rothman RE, Patel EU, Laeyendecker $\mathrm{OB}$, Marzinke MA, et al. Improvements in the continuum of HIV care in an inner-city emergency department. AIDS. 2016;30:113-20.

64. Bocour A, Renaud TC. Udeagu C-CN, Shepard CW. HIV partner services are associated with timely linkage to HIV medical care. AIDS. 2013;27:2961-3.

65. Centers for disease control and prevention. National HIV and STD testing resources. Rockville: CDC National Prevention Information Network; 2015.

66. Azavea. OpenDataPhilly. Philadelphia: OpenDataPhilly.org; 2015.

67. Environmental Systems Research Institute (ESRI). ArcGIS Help: Release 10.1 Near Analysis. Redlands: Environmental Systems Research Institute; 2015.

68. Environmental Systems Research Institute (ESRI). ArcGIS Desktop: Release 10.2. Redlands; 2014.

69. Anselin L, Ibnu S, Youngihn K. GeoDa: an introduction to spatial data analysis. Geogr Anal. 2006;38:5-22.

70. Takagi D, Ikeda KI, Kawachi I. Neighborhood social capital and crime victimization: comparison of spatial regression analysis and hierarchical regression analysis. Soc Sci Med. 2012;75:1895-902.

71. Kruger DJ, Hutchison P, Monroe MG, Reischl T, Morrel-Samuels S. Assault injury rates, social capital, and fear of neighborhood crime. J Community Psychol. 2007;35:483-98.

72. Bauman LJ, Braunstein S, Calderon Y, Chhabra R, Cutler B, Leider $\mathrm{J}$, et al. Barriers and facilitators of linkage to HIV primary care in New York City. J Acquir Immune Defic Synd. 2013;64:S20-6.
73. Messer LC, Quinlivan EB, Parnell H, Roytburd K, Adimora AA, Bowditch N, et al. Barriers and facilitators to testing, treatment entry, and engagement in care by HIV-positive women of color. AIDS Patient Care ST. 2013;27:398-407.

74. Myers JJ, Koester KA. Dufour M-SK. Barriers and facilitators to enhancing HIV testing in publicly funded primary care clinics: findings from San Francisco. AIDS Educ Prev. 2011;23:84-95.

75. Gant Z, Lomotey M, Hall H, Hu X, Guo X, Song R. A countylevel examination of the relationship between HIV and social determinants of health: 40 states, 2006-2008. Open AIDS J. 2012;6.

76. Centers for Disease Control and Prevention. Social determinants of health among adults with diagnosed HIV infection in 18 areas, 2005-2009. In: HIV Surveillance Supplemental Report. Atlanta: CDC; 2013. pp. 1-28.

77. Trepka MJ, Fennie KP, Sheehan DM, Lutfi K, Maddox L, Lieb S. Late HIV diagnosis: differences by rural/urban residence, Florida, 2007-2011. AIDS Patient Care ST. 2014;28:188-97.

78. Harrison KM, Ling Q, Song R, Hall HI. County-level socioeconomic status and survival after HIV diagnosis, United States. Ann Epidemiol. 2008;18:919-27.

79. Bureau USC. American FactFinder. U.S. Census Bureau; 2015.

80. Environmental Systems Research Institute (ESRI). ArcGIS Help: Release 10.1 What is areal interpolation. Redlands: Environmental Systems Research Institute; 2015.

81. Ransome Y, Kawachi I, Braunstein S, Nash D. Structural inequalities drive late HIV diagnosis: the role of black racial concentration, income inequality, socioeconomic deprivation and HIV testing. Health Place. 2016. doi:10.1016/j.healthplace. 2016.09.004.

82. Environmental Systems Research Institute (ESRI). ArcGIS Help: Release 10.1 Using areal interpolation to perform polygon to polygon predictions. Redlands: Environmental Systems Research Institute; 2015.

83. Scott LM, Janikas MV. Spatial statistics in ArcGIS. In: Fischer M, Getis A, editors. Handbook of applied spatial analysis: Software tools, methods, and applications. New York: Springer; 2010. p. 27-41.

84. StataCorp. Stata Statistical Software: Release 14.1. In. College station, TX: StataCorp LP; 2015.

85. Ransome Y, Galea S, Pabayo R, Kawachi I, Braunstein S, Nash D. Social capital is associated with late HIV diagnosis: an ecological analysis. J Acquir Immune Defic Syndr. 2016;73:213-21.

86. Campbell C, Williams B, Gilgen D. Is social capital a useful conceptual tool for exploring community level influences on HIV infection? An exploratory case study from South Africa. AIDS Care. 2002;14:41-54.

87. Skovdal M, Ogutu VO. Coping with hardship through friendship: the importance of peer social capital among children affected by HIV in Kenya. Afr J AIDS Res. 2012;11:241-50.

88. Grønlie AA, Dageid W. Subjective well-being among HIVpositive South Africans: the influence of resilience and social capital. Soc Indic Res 2016;1-18.

89. Takahashi LM, Magalong MG. Disruptive social capital: (un) healthy socio-spatial interactions among Filipino men living with HIV/AIDS. Health Place. 2008;14:182-97.

90. Portes A, Landolt P. The downside of social capital. Am Prospect. 1996;26:18-22.

91. Portes A. Social capital: its origins and applications in modern sociology. Annu Rev Sociol. 1998;24:1-24.

92. Smith RA, Rimal R. The impact of social capital on HIV-related actions as mediated by personal and proxy efficacies in Namibia. AIDS Behav. 2008;13:133-44.

93. Holt CL, Clark EM, Wang MQ, Williams BR, Schulz E. The religion-health connection among African Americans: what is 
the role of social capital? J Community Appl Soc Psychol. 2015;25:1-18.

94. Wilson PA, Wittlin NM, Muñoz-Laboy M, Parker RG. Ideologies of black churches in New York City and the public health crisis of HIV among Black men who have sex with men. Glob Public Health. 2011;6:S227-42.

95. Millett GA, Jeffries WL, Peterson JL, Malebranche DJ, Lane T, Flores SA, et al. Common roots: a contextual review of HIV epidemics in black men who have sex with men across the African diaspora. Lancet. 2012;380:411-23.

96. Dean LT, Subramanian SV, Williams DR, Armstrong K, Zubrinsky Charles C, Kawachi I. Getting black men to undergo prostate cancer screening: the role of social capital. Am J Mens Health. 2014.

97. Dean L, Gilbert K. Social Capital and Political Advocacy for African-American Health. Harv J Afr Am Public Policy. 2010;16:85.

98. Kaschula S. Using people to cope with the hunger: social networks and food transfers amongst HIV/AIDS afflicted households in KwaZulu-Natal, South Africa. AIDS Behav. 2011;15:1490-502.

99. Kalichman SC, Hernandez D, Cherry C, Kalichman MO, Washington C, Grebler T. Food insecurity and other poverty indicators among people living with HIV/AIDS: effects on treatment and health outcomes. J Community Health. 2014;39:1133-9.

100. Sampson R, Raudenbush S, Earls F. Neighborhoods and violent crime: a multilevel study of collective efficacy. Science. 1997;277:918-24.

101. Svendsen GLH. Social capital: Provoking, promising, and problematic. In: Gupta KR, Svedsen GLH, Mati P, editors. Social capital. New Delhi: Atlantic Publishers and Distributors (P) LTD; 2008. pp. 115-157.

102. Szreter S, Woolcock M. Health by association? Social capital, social theory, and the political economy of public health. Int $\mathbf{J}$ Epidemiol. 2004;33:650-67.

103. Uphoff EP, Pickett KE, Cabieses B, Small N, Wright J. A systematic review of the relationships between social capital and socioeconomic inequalities in health: a contribution to understanding the psychosocial pathway of health inequalities. Int $\mathbf{J}$ Equity Health. 2013;12:54.
104. Hutchinson RN, Putt MA, Dean LT, Long JA, Montagnet CA, Armstrong K. Neighborhood racial composition, social capital and black all-cause mortality in Philadelphia. Soc Sci Med. 2009;68:1859-65.

105. Altschuler A, Somkin CP, Adler NE. Local services and amenities, neighborhood social capital, and health. Soc Sci Med. 2004;59:1219-29.

106. Cornish F, Priego-Hernandez J, Campbell C, Mburu G, McLean $\mathrm{S}$. The impact of community mobilisation on HIV prevention in middle and low income countries: a systematic review and critique. AIDS Behav. 2014;18:2110-34.

107. Baum F. Social capital: is it good for your health? Issues for a public health agenda. J Epidemiol Community Health. 1999;53:195-6.

108. Stephens C. Social capital in its place: using social theory to understand social capital and inequalities in health. Soc Sci Med. 2008;66:1174-84.

109. Frumence G, Eriksson M, Nystrom L, Killewo J, Emmelin M. Exploring the role of cognitive and structural forms of social capital in HIV/AIDS trends in the Kagera region of Tanzania-a grounded theory study. Afr J AIDS Res. 2011;10:1-13.

110. Fotheringham AS, Wong DWS. The modifiable areal unit problem in multivariate statistical analysis. Environ Plan A. 1991;23:1025-44.

111. Bracken I. An extensive surface model database for populationrelated information: concept and application. Environ Plan B. 1993;20:13-27.

112. Trute B, Segal SP. Census tract predictors and the social integration of sheltered care residents. Soc Psychiatry. 1976;11:153-61.

113. Krieger N, Zierler S, Hogan JW, Waterman PD, Chen JT, Lemieux K, et al. Geocoding and measurement of neighborhood socioeconomic position: A U.S. perspective. In: Kawachi I, Berkman L, editors. Neighborhoods and health. New York: Oxford University Press; 2003. pp. 147-178.

114. Shepard CW, Gortakowski HW, Nasrallah H, Cutler BH, Begier EM. Using GIS-based density maps of HIV surveillance data to identify previously unrecognized geographic foci of HIV burden in an urban epidemic. Public Health Rep. 2011;126:741-9. 